November 2020

\title{
Making the Invisible Visible: Enhancing Information Literacy and Metacognition with a Constructivist Activity
}

Jessica Denke

Muhlenberg College, jessicadenke@muhlenberg.edu

Jennifer Jarson

Penn State University, Lehigh Valley, jmj12@psu.edu

Stefanie Sinno

Muhlenberg College, stefaniesinno@muhlenberg.edu

Follow this and additional works at: https://digitalcommons.georgiasouthern.edu/ij-sotl

\section{Recommended Citation}

Denke, Jessica; Jarson, Jennifer; and Sinno, Stefanie (2020) "Making the Invisible Visible: Enhancing Information Literacy and Metacognition with a Constructivist Activity," International Journal for the Scholarship of Teaching and Learning: Vol. 14: No. 2, Article 7.

Available at: https://doi.org/10.20429/ijsotl.2020.140207 


\title{
Making the Invisible Visible: Enhancing Information Literacy and Metacognition with a Constructivist Activity
}

\author{
Abstract \\ A growing body of literature focused on the pedagogical relationship between information literacy (IL) and \\ metacognition suggests that facilitating learners' reflections promotes IL learning. However, activating \\ and assessing this relationship is difficult. This article describes a constructivist activity that models for \\ students how to practice IL while increasing awareness of metacognitive approaches. The modified \\ jigsaw activity, including a worksheet, facilitates individual reflection and peer-to-peer learning through \\ structured conversation regarding popular press articles. Using a grounded theory approach, coding of \\ students' worksheets showed IL development related to comprehension, procedure, evaluation, and \\ reflection. Moreover, the worksheet offers instructors insight into student learning processes and \\ progress. This article offers evidence of how to enhance and make more visible the connection between \\ $\mathrm{IL}$ and metacognition for both students and instructors.
}

\section{Keywords}

metacognition, reflection, information literacy, constructivist pedagogy, information evaluation, peer-topeer learning

\section{Creative Commons License} c) (i) $९$

This work is licensed under a Creative Commons Attribution-Noncommercial-No Derivative Works 4.0 License. 


\title{
Making the Invisible Visible: Enhancing Information Literacy and Metacognition with a Constructivist Activity
}

\author{
Jessica Denke, 'Jennifer Jarson, ${ }^{2}$ and Stefanie Sinno' \\ I Muhlenberg College \\ 2 Penn State University, Lehigh Valley
}

Received: 27 April 2020;Accepted: 21 September 2020

\begin{abstract}
A growing body of literature focused on the pedagogical relationship between information literacy (IL) and metacognition suggests that facilitating learners' reflections promotes IL learning. However, activating and assessing this relationship is difficult. This article describes a constructivist activity that models for students how to practice IL while increasing awareness of metacognitive approaches. The modified jigsaw activity, including a worksheet, facilitates individual reflection and peer-to-peer learning through structured conversation regarding popular press articles. Using a grounded theory approach, coding of students' worksheets showed IL development related to comprehension, procedure, evaluation, and reflection. Moreover, the worksheet offers instructors insight into student learning processes and progress. This article offers evidence of how to enhance and make more visible the connection between IL and metacognition for both students and instructors.
\end{abstract}

Information literacy (IL) and metacognition are essential skills for success in higher education and the workplace globally (Vivekanandan, 2019; Wald, 2019; Weiner, 20I I). These skills, grounded in critical thinking and reflection, improve individuals' ability to handle complexity (Weiner, 20I I). IL is a "fundamental part of students' broader skill set that will help them be effective and responsible users and creators of information, both in college and beyond" (Wiebe, 2016, "Information literacy as a liberal art," para. 4). Recent surveys have shown that employers rank IL skills and skills related to IL as very important for college graduates (Hart Research Associates, 20 I5; Raish \& Rimland, 20I6), yet have suggested that employers find new graduates lack advanced IL skills (Head, 2012).

Scholars have emphasized the importance of teaching these skills in the classroom (Hepworth \& Walton, 2009; Wiebe, 2016); however, the literature suggests that it can be challenging for instructors to know if their assignments are effectively fostering students' development of these skills (Fulkerson, Ariew, \& Jacobson, 2017). This article explores how using a constructivist pedagogy can increase the visibility of the connection between metacognition and IL for students and educators to promote teaching and learning.

\section{Defining Metacognition, Reflection, and Information Literacy}

Metacognition refers to the ability to monitor and regulate one's learning (Lai, 20 I I). Researchers have often classified metacognitive activities into two components: knowledge and regulation (Schraw \& Dennison, 1994). Cognitive knowledge refers to self-awareness and self-appraisal of cognition, whereas cognitive regulation refers to planning, monitoring or regulating, and evaluating skills (Lai, 20 I I; Moseley et al., 2004; Veenman, Van Hout-Wolters, \& Afflerbach, 2006). Encouraging students to practice awareness and management of their thinking and learning can support their development of critical thinking skills and their ability to transfer and apply knowledge and skills in new situations (Kuhn \& Dean, 2004).

Reflection and reflective practice are integral to metacognition. Hepworth and Walton (2009) and Harvey, Coulson, and McMaugh (2016) both highlight the important role of reflective practice in learning and its contributing role to metacognitive development. The integration of intentional reflective practice into teaching and learning can support the development of self-awareness (Sandars, 2009; Tsang, 20I I). Mentors and/or peers can play an important role in challenging and supporting learners to guide reflection (Sandars, 2009).

The Association of College and Research Libraries (ACRL) (20I5) Framework for Information Literacy for Higher Education characterizes IL as the concepts, skills, and attitudes related to critically consuming and producing information. IL is important to student learning in a wide variety of disciplines (Weiner, 20I I).As Booth (20II) states, "information literacy is inherently metacognitive" (p. 18); therefore, developing the pedagogical relationship between IL and metacognition can be advantageous for students and instructors.

The ACRL (20I5) Framework is widely used in higher education in the United States to inform IL teaching and learning. The Framework offers six core IL concepts, or frames, related to the information ecosystem: Authority is Constructed and Contextual, Information Creation as a Process, Information Has Value, Research as Inquiry, Scholarship as Conversation, and Searching as Strategic Exploration. The integral nature of metacognition in IL learning is both explicit and implicit in the Framework (ACRL, 20I5; Fulkerson et al., 20I7). The IL work described in this article focuses on developing students' understanding of information evaluation, an aspect of IL informed by the Authority is Constructed and Contextual frame. This frame positions the authority of information sources and creators as dependent on the circumstances and environment of their production and consumption, rather than absolute (ACRL, 20I5). The frame asks that learners engage with both the content and context of sources, 
thinking deeply about the systems in which information is created. The frame also suggests that learners who are developing IL skills and attitudes should critically reflect on their own information needs--how and why they engage with those sources--when determining the value of an information source. Thinking critically about the context of one's information needs depends upon metacognitive skills, as it demands self-awareness and self-appraisal.

\section{Pedagogical Approaches for Metacognition}

Asking students to complete written reflections is a common method of incorporating reflective practice in higher education. Reflective writing can range from brief (e.g., one-minute or muddiest point papers) to intermediate (e.g., journals and diaries) to extended (e.g., portfolios) (Fink, 20l3). Reflective writing is used in a variety of disciplines such as teacher education (Slade, Burnham, Catalana, \& Waters, 2019), social work education (McGuire, Lay, \& Peters, 2009), and health professions education (Wald \& Reis, 20I0) in order to promote understanding of subject content, as well as self-awareness and critical thinking. In-class reflective group discussion can be a productive and valuable complement to individual reflective writing (Tsang, 20I I).

A growing body of literature focused on the pedagogical relationship between IL and metacognition/reflection suggests that facilitating learners' reflections promotes and deepens their IL learning. Houtman (2015) describes the use of reflective "wrapper" activities in research skills workshops to promote students' learning and IL development. McKinney and Sen (20I2) discuss the impact of reflective writing assignments on students' IL learning in an undergraduate business course. Whitver and Riesen (2019) explore the use of reflection activities in library instruction sessions to assist students' application and transference of IL skills and concepts.

However, articulating and activating this relationship is difficult.Asking learners to reflect on their process and their thinking requires them to make "what is normally invisible more visible" (Fulkerson et al., 2017, p. 33). Learners, as Whitver and Riesen (2019) suggest, "may not know how to reflect" (p. 27I). Providing students with guiding questions may be one useful way to help them reflect (Moussa-Inatay, 2015). Pee, Woodman, Fry, \& Davenport (2002) also found that guiding questions in a structured worksheet format helped students reflect at a deeper level This project builds on past literature to explore the pedagogical approach of teaching reflective practices using guided worksheets in an IL context.

\section{Constructivist Pedagogy}

Pedagogy grounded in constructivism generally features active learning through real-world connections or application and peerto-peer learning (Booth, 201 I). Instructors have an active role in guiding students to develop their understanding through experience and reflection; teaching strategies that scaffold experience and reflection help students develop advanced reflective skills (Harvey et al., 2016). Hepworth and Walton (2009) point to the importance of structured reflective practice to build from learners' pre-existing knowledge, illustrating the elemental role of metacognition for advancing IL learning with constructivist pedagogy.

In one of the most common models of IL instruction, the "one shot," librarians work with students in a single 50 - or 75-minute class period in order to introduce research tools and strategies related to an assignment. Cooperstein and Kocevar-Weidinger (2004) describe some of the limitations of this model that may inhibit librarians from designing instruction grounded in constructivist principles such as the small window of time available and the amount of information that must be made understandable to students. Yet they also advocate for its use given the benefits it offers:"although difficult and time consuming, ... carefully planned, structured, directed [constructivist] activities lead students to discover concepts and develop skills. Abstract concepts become meaningful, transferable, and retained.... The activities lead to concepts; the students construct the meaning" (p. 145). Creating activities in which students construct meaning based on their prior knowledge and make new connections facilitates their active engagement. Such student-centered activities can foster IL growth through metacognition. These activities, such as the one described here, can be designed and implemented in manageable ways.

By participating in and observing students in these constructivist activities, instructors are also able to conduct formative assessment that "help[s] uncover students' thinking and assumptions - for themselves and for us as instructors - that might otherwise have remained hidden" (Sinno \& Jarson, 2018, p. 96). Thus, an engaged, constructivist approach, as outlined in this article, allows for greater student learning and increased instructor understanding of students' learning.

\section{CURRENT STUDY}

This article describes the implementation and assessment of a scaffolded, constructivist activity that models for students how to practice metacognition and IL.We selected popular press articles related to psychology in order to ground the activity in content relevant to the course subject matter yet accessible for introductory level students. We developed a modified jigsaw pedagogical approach which had been implemented successfully for several semesters prior to this research project (Sinno \& Jarson, 20l8). We adapted the approach and, crucially, added an active learning worksheet in this iteration to further facilitate individual reflection, peer-to-peer learning, and transparency of student progress. The metacognitive framework of this worksheet made students' IL thinking more visible to them and to us. In order to analyze students' development of IL skills and practices, we examined their responses throughout the activity using a grounded theory approach. This approach allowed students' behaviors and thinking to emerge during analysis, rather than be biased by teacher expectations. This article describes the constructivist activity and provides evidence of its effectiveness, highlighting the relationship between IL and metacognition and the significance of IL conversations within the higher education classroom.

\section{METHODS \\ Participants}

A total of 129 traditional-aged, full-time undergraduate college students participated in the scaffolded activity during in-class IL sessions. Students (74 first-year, 38 sophomore, 10 junior, and 7 senior) were enrolled in six sections of Introduction to Psychology, with an average of 21 students per section. The project was approved by the Institutional Review Board and all students gave consent for their worksheets to be included anonymously in the analysis. 


\section{Procedure}

In the class session prior to the scaffolded IL session, each faculty instructor randomly divided students into five groups and assigned members of each group to read one of five selected popular press articles as homework. We had chosen the articles (see Table I) from websites noted to be the most popular among current college students (Doctor, 2016; Priceonomics Data Studio, 2017). The articles were related to psychology concepts covered later in the semester, similar in length, and written in an accessible style.

\begin{tabular}{|l|l|l|}
\hline \multicolumn{3}{|l|}{ Table I. Popular press articles assigned in activity } \\
\hline Source & Title & Summary \\
\hline $\begin{array}{l}\text { BuzzFeed } \\
\text { (MBarden93, 20I8) }\end{array}$ & $\begin{array}{l}\text { Social media: } \\
\text { Making or breaking } \\
\text { pro athletes? }\end{array}$ & $\begin{array}{l}\text { The benefits and costs } \\
\text { of college and profes- } \\
\text { sional athletes' use of } \\
\text { social media }\end{array}$ \\
\hline $\begin{array}{l}\text { Vox } \\
\text { (Lopez, 2018) }\end{array}$ & $\begin{array}{l}\text { A new study shows } \\
\text { stigma is hurting } \\
\text { our response to } \\
\text { the opioid epidemic }\end{array}$ & $\begin{array}{l}\text { Stigma toward people } \\
\text { who are addicted to } \\
\text { opioids is related to } \\
\text { attitudes toward needle } \\
\text { exchanges and safe } \\
\text { injection sites }\end{array}$ \\
\hline $\begin{array}{l}\text { Mic } \\
\text { (Kasulis, 2018) }\end{array}$ & $\begin{array}{l}\text { It's official: } \\
\text { Excessive gaming is is } \\
\text { now recognized as } \\
\text { a health disorder } \\
\text { been added to the } \\
\text { World Health Organiza- } \\
\text { tions' disease classifi- } \\
\text { cation }\end{array}$ \\
\hline $\begin{array}{l}\text { Ozy } \\
\text { (Graber-Stiehl, } \\
\text { 20I8) }\end{array}$ & $\begin{array}{l}\text { This sci-fi tool lets } \\
\text { you shine a light on } \\
\text { the brain }\end{array}$ & $\begin{array}{l}\text { Optogenetics can help } \\
\text { to control neurons and } \\
\text { impact nerve regener- } \\
\text { ation }\end{array}$ \\
\hline $\begin{array}{l}\text { Refinery20 } \\
\text { (Stieg, 20I8) }\end{array}$ & $\begin{array}{l}\text { Should you wake } \\
\text { up early to work } \\
\text { out or sleep in? }\end{array}$ & $\begin{array}{l}\text { The benefits and costs } \\
\text { of enough sleep and } \\
\text { enough exercise }\end{array}$ \\
\hline
\end{tabular}

During the IL session, two of the project researchers led students through the planned activity. The activity followed a modified jigsaw pedagogical format (Social Psychology Network, 2020), which required students to reflect on their assigned article individually (Part A), meet with others who had read the same article (Part B), and then meet with students who had read different articles (Part C). The students engaged in individual reflection on their worksheets between each step of the process in order to practice metacognitive thinking (see Appendix A). Each step of the activity promoted increasingly abstract thinking about information evaluation. The worksheet created space for additional insight into students' use of IL skills and the process of metacognitive thinking.

During the first phase of the activity (Part A), students individually reflected on their own reading process. The worksheet (see Appendix A) prompted them to summarize their assigned articles, assess the articles' strengths and weaknesses, and describe their reactions to the articles. Then students reflected on their approaches to reading and thinking about the article, responding to the first guiding question of the project: How did you get to your conclusion? (e.g., What steps did you take? What did you think about?). In Part B, students met with others assigned the same article to discuss their Part A responses and develop expertise with their assigned articles. After the group discussion, they individually reflected on the second guiding question: What advice would you give other students about how to read, analyze, and evaluate this article? Finally, students moved into "jigsaw" groups in Part C in which they met with students who read different articles. In this stage, they each served as the group's sole "expert" on their article. They shared information about both the content of their varying articles and reading/thinking approaches. Each group documented highlights from their conversations on the board in response to three prompts: (I) overlaps and (2) differences in their evaluation of and reflection on the articles, as well as (3) the advice they might give students about evaluating any article. They also individually reflected and responded to the third guiding question: Now that you've discussed a variety of articles, what advice would you give other students about how to read, analyze, and evaluate any article? Finally, as a larger class group, we moderated a discussion among students starting from the notes they had added to the board. The discussion focused on identifying themes and strategies, framed as "best practices," for improving evaluation skills while reading popular press articles.

\section{Grounded Theory Analysis}

Students' written responses to the three guiding questions on the worksheet were transcribed by research assistants. Given the exploratory nature of uncovering how students were thinking about their evaluation of popular press articles, we employed a grounded theory approach to the students' worksheet responses (Strauss \& Corbin, 1994). In line with grounded theory, all transcribed responses were read thoroughly and repeatedly in order to search for emerging patterns in students' thinking. Our process of coding involved three major phases: a "keyword" search, an initial thematic organization of responses, and final coding of IL themes.

Important to grounded theory, in the first phase, each researcher conducted an in-depth content analysis (Morse, 200I), listing all the words or phrases in the students' own responses that stood out to us as educators. In this phase, we focused on the concepts underlying IL, informed by the Framework (ACRL, 20I5), to search for keywords. For example, students' references to the authors' perspectives and expertise related to the Authority is Constructed and Contextual Frame were highlighted as meaningful.While the knowledge practices and dispositions outlined in the Framework informed this work, they were not used as explicit guidelines for coding. Instead, we allowed students' own words to direct our inquiry and began to think about the conceptual organization into which their words might fit. At the conclusion of this phase, we marked overlaps between students' responses within and across questions.

Analysis of the keywords that emerged revealed that students' responses most often related to themes of procedure, evaluation, and reflection. Therefore, in the second phase of coding, we used this initial set of thematic codes and worked through how these codes would apply, align, and explain students' worksheet reflections. We went back to the transcribed student responses, applied the thematic codes, and highlighted the keywords that students used that led to assigning that theme. We assigned as many thematic codes as we thought necessary for each response. Each researcher coded all of the responses individually. We then exchanged sets, removing all past codes so we could not see the other researchers' coding, and came together to compare for consistencies or discrepancies in interpretation of students' writing. This process led to the additional theme of comprehension as there were some student responses that focused only on summarizing or understanding the content of the article.

The final phase was the development and implementation of a detailed coding scheme that was created through the above 
iterative process (Charmaz \& Belgrave, 20I5).We examined the defining keywords and characteristics that led to the development of the thematic codes and refined those into sub-theme codes for the final detailed coding phase. Most themes included five to six sub-theme codes (see Table 2). The comprehension theme refers to students' summary or understanding of article content. The procedural theme refers to students' descriptions of their behaviors, the steps they took, and the strategies they employed. The evaluation theme refers to students' descriptions and assessments of the article's use of evidence, purpose, and audience. The reflection theme refers to students' recognition of their own personal knowledge, ideas, and feelings. Each researcher read through all student responses looking for sub-themes. We then switched to another theme to cross-analyze. There was a strong rate of inter-rater reliability, with our agreement ranging from 57\%- $96 \%$. Agreements steadily increased from guiding question I to guiding question 3. Discrepancies were highlighted and read through one more time and discussed if needed.

\begin{tabular}{|c|c|}
\hline Primary thematic codes & Sub-theme codes \\
\hline $\begin{array}{l}\text { Comprehension: } \\
\text { Summary and content }\end{array}$ & Not applicable \\
\hline $\begin{array}{l}\text { Procedure: } \\
\text { Behaviors and strategies }\end{array}$ & $\begin{array}{l}\text { - Article elements } \\
\text { - Asking questions } \\
\text { - Meaning making } \\
\text { - Note behaviors } \\
\text { - Outside research } \\
\text { - Reading }\end{array}$ \\
\hline $\begin{array}{l}\text { Evaluation: } \\
\text { Assessment of evidence, } \\
\text { purpose, and audience }\end{array}$ & $\begin{array}{l}\text { - Audience } \\
\text { - Author perspective } \\
\text { - Evidence and reliable sources } \\
\text { - Presentation of argument } \\
\text { - Statistical reliability } \\
\end{array}$ \\
\hline $\begin{array}{l}\text { Reflection: } \\
\text { Recognition of personal } \\
\text { knowledge, ideas, and feelings }\end{array}$ & $\begin{array}{l}\text { - Personal ideas and beliefs } \\
\text { - Prior knowledge } \\
\text { - Life experience } \\
\text { - Open mind / multiple } \\
\text { perspectives } \\
\text { - Thoughts/ feelings } \\
\end{array}$ \\
\hline
\end{tabular}

\section{RESULTS}

The procedure, evaluation, and reflection themes were evident throughout the activity, increasing in frequency with each phase as noted in Table 3. The comprehension theme was evident primarily in responses to guiding question one (Part $A$ ). In student responses to guiding question one of the activity, evidence of just one theme was most common. By guiding question three (Part C), students' responses were more robust showing evidence of two or three themes as seen in the increasing total number of codes from question one to question three in Table 3.

\begin{tabular}{|l|c|c|c|c|}
\hline Table 3. Themes from student responses to guiding questions \\
\hline & Question I & Question 2 & Question 3 & Total \\
\hline Comprehension & 15 & $\mathrm{I}$ & 0 & 16 \\
\hline Procedure & 37 & 57 & 86 & 180 \\
\hline Evaluation & 28 & 54 & 58 & 140 \\
\hline Reflection & 47 & 53 & 88 & 188 \\
\hline Not codable & 10 & $\mathrm{I}$ & $\mathrm{I}$ & 12 \\
\hline Total & 137 & 166 & 233 & 536 \\
\hline
\end{tabular}

\section{Comprehension}

The comprehension theme refers to students' summary or understanding of article content. Evidence of the comprehension theme was limited and largely confined to responses to guiding question I in Part A (see Table 3). Students responded with comments such as "Reading the article and understanding what they were saying" or simply repeated the main purpose of their assigned article.

\section{Procedure}

The procedure theme refers to students' descriptions of their behaviors, steps they took, and strategies they employed. Six IL-related codes emerged under the umbrella of this theme: (I) identifying and using article elements, (2) asking questions, (3) making meaning, (4) employing various behaviors related to taking notes or interacting with texts, (5) conducting outside research, and (6) reading. Evidence of each of the six sub-theme codes generally increased across the guiding questions, as noted in Figure I.The degree of increase varied and in the case of two codes-reading and meaning making-essentially plateaued between guiding questions two and three.

Students described reading, re-reading, and analyzing articles, as well as summarizing, re-stating, or otherwise interpreting and recalling information as a strategy to make meaning of the articles. Their descriptions of their reading behaviors or advice regarding reading varied from limited (e.g., "I re-read the article") to somewhat more robust (e.g., "I read the questions before I started reading the passage so I could find the answers while reading"). In addition to reading, students also described summary-type strategies to make meaning. For example, one student advised, "Make sure you are able to reiterate the claims made in the article correctly in order to make sure you truly understand."

Students increasingly referred to particular aspects or elements of the articles as important to their process through the activity phases. These included features (e.g., "bolded words"), structures (e.g.,"paid attention to how the article was divided in order to notice the different opinions"), and publication characteristics (e.g., "look at source of article"). Students also increasingly referred to a variety of note-taking behaviors, such as underlining, circling, or highlighting to make important points stand out through the activity phases. They sometimes also described adding comments to the articles, such as "annotate[d] with own thoughts and reflections about the information in order to draw conclusions."

When students described posing questions to themselves as a strategy to help them engage with the articles, it was most often in general terms. One student wrote, for example, “Don't just read the article and be done with it, ask questions, think about what you learned and what you still want to know." In order to comprehend or interpret the articles, students also described conducting outside research or consulting other sources. One student advised, for example, "use the internet to look up terms/ ideas that are unclear or unfamiliar."

\section{Evaluation}

The evaluation theme refers to students' descriptions and assessments of the articles' use of evidence, purpose, and audience. Five IL-related codes emerged under the umbrella of this theme: (I) acknowledging the audience and their possible bias(es), (2) awareness of the authors' perspective or possible bias, (3) evaluating evidence and reliability of sources generally, (4) critiquing the 


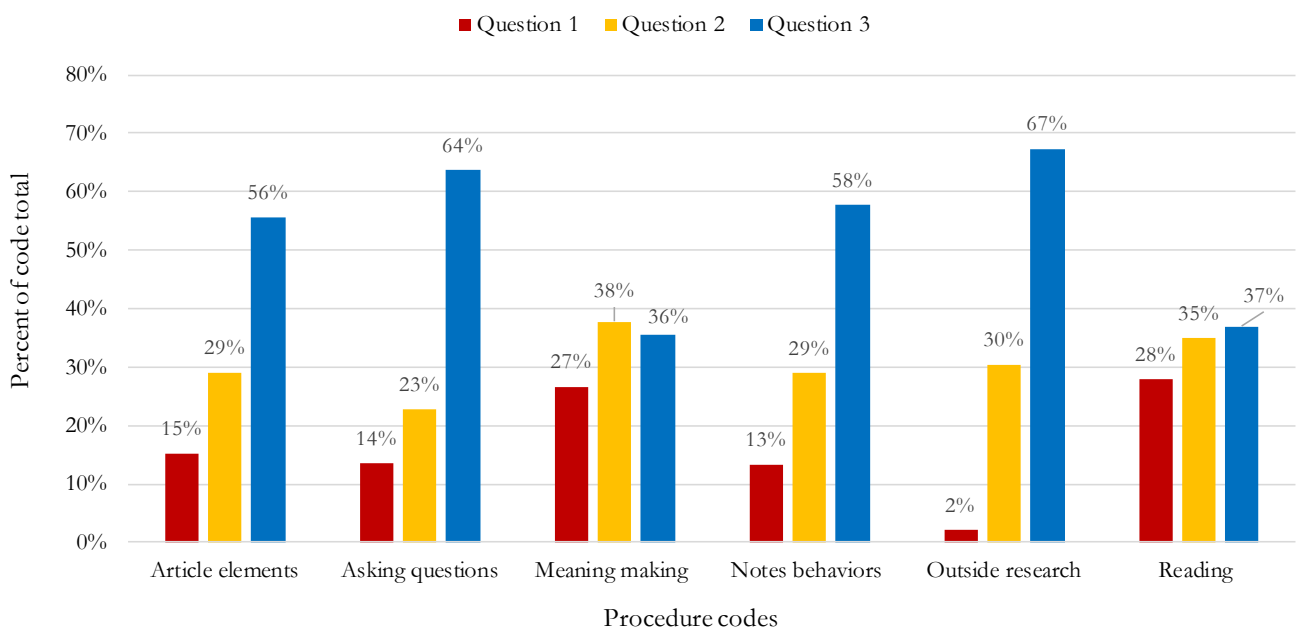

Figure I. Procedure sub-theme codes from students' responses by guiding question

presentation of arguments made by authors, and (5) evaluating statistical reliability specifically. Evidence of the five sub-theme codes increased across the questions except in the area of the presentation of arguments, as noted in Figure 2. By the final guiding question, students' responses showed evidence of multiple sub-theme codes. For instance, one student responded that students should "(I) look for hard evidence (numbers + stats), (2) look for sources that are credible, (3) look for a purpose, (4) look for validity, (5) reread articles, (6) consider speaker, reader, + audience" when examining any article.

Students increasingly referred to the audience as they moved through the activity.As students progressed from focusing on one article (guiding questions I and 2) toward broader evaluation (guiding question 3), they were more likely to suggest, for example, "considering who the intended audience" might be before evaluating the article as a whole. Students' discussion of evaluating authors' perspectives and possible biases also increased as they moved through the activity. We saw this most often in responses to guiding question three, when students advised others to, for example, "avoid blindly following author claims" or "Pay attention to cited sources and whether or not there are sources present. Take a moment to think about the language the author used and who their respective audience is."
Some students' responses emphasized evaluation of evidence and the reliability of sources. For instance, "Look at the details. Know if what you are reading is reliable." There were changes in students' thinking within the evaluation theme such that in guiding question one, students were more likely to note the existence of evidence (e.g., "Didn't have any strong evidence or details"). By guiding question three, when asked to provide advice about reading any article, students' discussion of evidence was more robust. For example, one student wrote that "it is crucial to look at articles with ... a skeptical lens, as many articles may have incomplete or incoherent claims."

Students' focus on the presentation of the argument decreased across the three questions. In response to guiding question one, for example, students described the "look" of the article, such as "the evidence and writing style was poorly presented." By guiding question three, although less frequently seen, students advised others to think about not only the information provided but what might be "missing." In comparison, the focus on evaluating statistical reliability increased, yet their descriptions were typically limited (e.g., "look specifically at the data”).

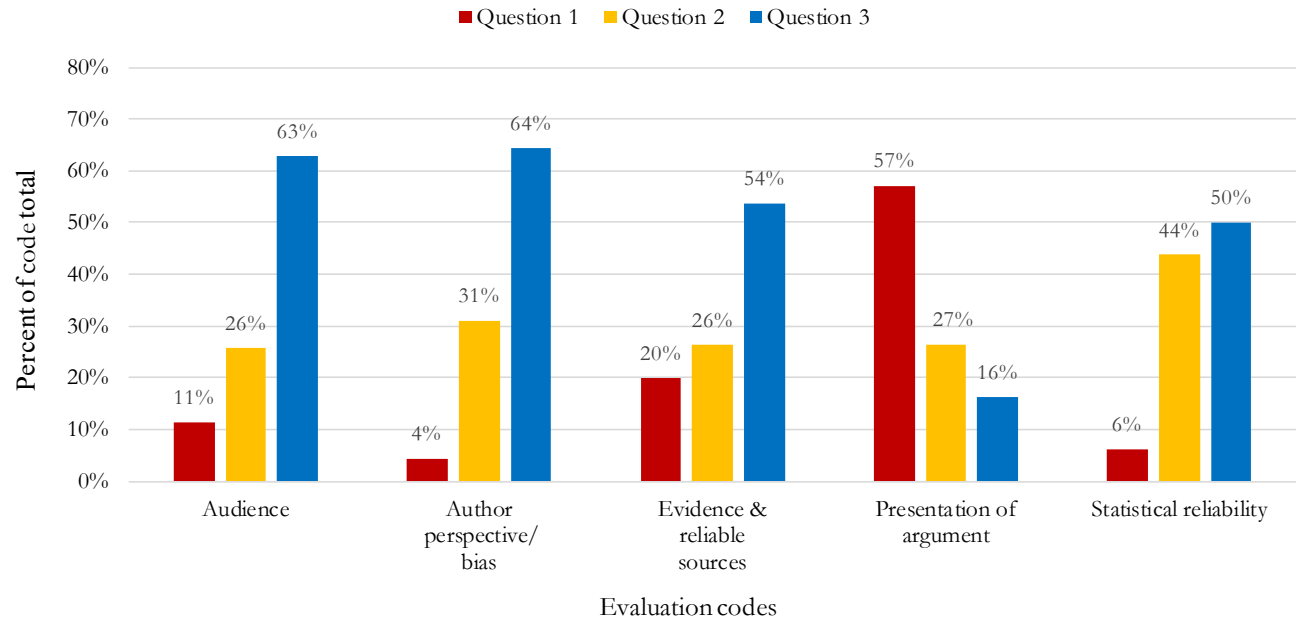

Figure 2. Evaluation sub-theme codes from students' responses by guiding question 


\section{Reflection}

The reflection theme refers to students' recognition of their own personal knowledge, ideas, and feelings. Five IL-related codes emerged under the umbrella of this theme: (I) acknowledgement of prior ideas/beliefs, (2) reference to knowledge, (3) reference to life experiences, (4) interest in maintaining an open mind/ considering all perspectives, and (5) reaction to article articulated as thoughts/feelings. Evidence of each of the five sub-theme codes in the reflection theme fluctuated more than in the case of the procedure and evaluation themes with each code following a different trajectory, as noted in Figure 3.

Students' responses demonstrated that reflection often built off of procedural IL-related practices through annotating reactions, questions, and comments throughout the process of reading the articles. Students' references to their ideas and beliefs centered around consideration of their preconceived notions and whether reading the assigned article might change them. One student advised to "identify your biases before reading the article" and another student reflected, "When you finish reading, decide if your beliefs changed." Evidence of students' acknowledgement of their beliefs and ideas increased sharply from guiding question one to two, but then remained steady into guiding question three.

Students also called on their own knowledge and past experiences to provide context for their reading or compared knowledge they gained by reading the assigned articles with prior knowledge. One student reflected,"I thought about similar stories I have heard about in the news." Another student advised, "focus on what you gained from reading the article and reflect on how it compares with what you already know." Evidence of student reflection related to their own knowledge remained flat from guiding question one to two, but then increased notably into guiding question three. When comparing their own experience to the articles, students typically wrote in general terms. For example, one student recommended, "Relate the message or information in the article to your own life/experience." Evidence of this code increased sharply from guiding question one to two but then dropped by guiding question three.

Students also described awareness of their thoughts and feelings. Sometimes this was noted as "positive," "negative," or "neutral," which, while brief, illustrates that students were aware of the ways that information was affecting their experience. Other students elaborated their thoughts and feelings about the article.
In some cases, students reflected on the impact of this awareness on their reading and interpretation. "It was hard to find a weakness since I liked the article so much and I had to think a bit harder," one student wrote."Question your emotional response," another advised. Evidence of this code was highest in guiding question one, dipped in guiding question two, then increased somewhat by guiding question three. Students described the importance of reading with an "open mind" and acknowledging their biases, largely in general terms. A few students were more specific, advising to "leave out any judgement, bias, or generalizations," for example. Evidence of this code increased dramatically from guiding question one to two and again significantly by guiding question three.

\section{DISCUSSION}

The current project aimed to promote students' IL development by encouraging metacognitive practice and to make more visible to students the connection between IL and metacognition. Past literature has noted the importance of guiding students through the process of reflection as they might not be aware of their own skills or be able to articulate their thinking process (Fulkerson et al., 2017; Whitver \& Riesen, 2019). By implementing a constructivist activity in an introduction to psychology course and through thematic coding of students' own responses, there was an increased visibility of students' IL skills through the work of metacognitive practice. Students' worksheet responses became more varied and robust as the activity progressed, suggesting movement toward broader perspectives on IL and increased critical thinking by the conclusion of the activity. By articulating their thinking through peer interactions and written reflections, students were being taught how to reflect and they began to recognize the behaviors and moves that helped them to be active and critical readers. This project contributes to the growing body of literature around pedagogical approaches for metacognition (Fink, 20I3) and the connections between IL and metacognition (Whitver \& Riesen, 2019) suggesting that by explicitly connecting them, even in a one-shot environment, both can be enhanced.

The practices and thinking made visible to the students through the worksheet responses, in particular, enriched their dialogue at each stage of the activity. The constructivist nature of the activity, starting with popular press articles that are more accessible to undergraduates and incorporating both individ-

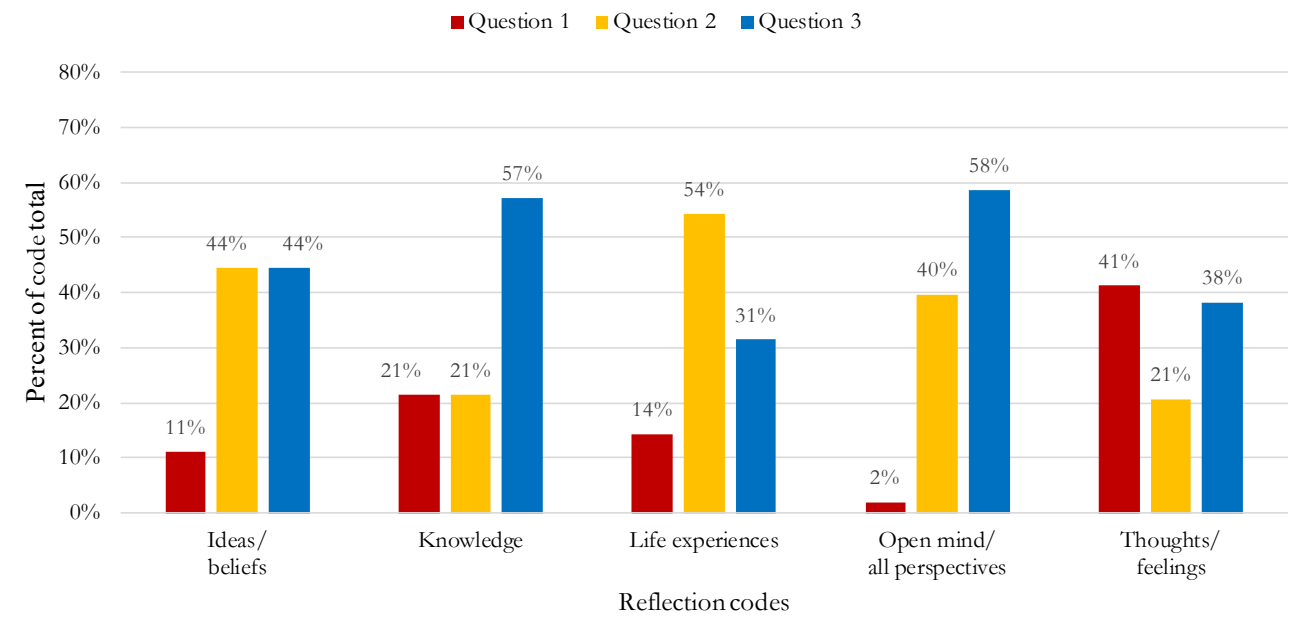

Figure 3. Reflection sub-theme codes from students' responses by guiding question 
ual reflection and group dialogue, facilitated students' connection-making and resulted in more engaged and advanced IL conversations. In prior iterations of this activity, the phases of the modified jigsaw pedagogy promoted students' IL understanding and development. The addition of the worksheet with guiding questions for this project made the structure and progression of the activity more visible for students, and allowed for deeper reflection (Moussa-Inatay, 20I5; Pee et al., 2002).

The addition of the worksheet also made students' thinking more visible to instructors and allowed for in-depth analysis using a grounded theory model. Through investigating students' responses, it became clear that students were incorporating IL skills. Three main themes emerged from students' responses: procedure, evaluation, and reflection. When responding to the first guiding question, which was written individually before conversation with others, some students also started with thinking about the importance of basic comprehension of the content. Many students' written responses in this first question showed that they were thinking about procedures they used to navigate popular press articles. The procedures mentioned by students indicated that they recognized that "authoritative content may be packaged formally or informally," as described in the Authority is Constructed and Contextual frame, and that remaining skeptical, asking questions, and considering the information package may help indicate value (ACRL, 20I5). As students moved through the rest of the jigsaw activity and conversed with their peers, their responses started to focus more on evaluation and reflection, or to combine multiple layers (i.e., themes) of IL skills. The final question, asking students to give advice to others about reading, analyzing, and evaluating any article, encouraged student metacognition by activating their knowledge and regulation. Students were able to appraise and pass along their best suggestions for article evaluation, demonstrating metacognitive regulation. They also returned to the guiding questions on their worksheets, allowing for repeated attempts at knowledge growth. Their consideration of evidence and authority of information presented, as well as their own thoughts, feelings, and prior knowledge, demonstrate metacognition. Thus, use of grounded theory identified IL knowledge practices that were both exposed and enhanced by metacognitive work.

The structure of the scaffolded activity, students' reflective writing on the worksheet at key stages in the activity, and the moderated dialogue facilitated metacognition, in that all these steps helped students to process and articulate their thoughts. While responding to guiding questions on the worksheet, students were thinking about the IL work they were already implementing and moved to elaborating and integrating multiple modes of IL. The guiding questions and reflective writing created space to make IL and metacognition more visible to students, serving as a model for their future use.

\section{IMPLICATIONS AND FUTURE DIRECTIONS}

Students' reflective writing on the worksheet throughout the activity highlighted their existing and developing IL skills. The worksheet--new in this iteration of this "one-shot" constructivist activity--provided a clear, guided outline for students to follow, making metacognitive processes more explicit. The versatility of this assignment in developing students' IL skills and making the process of IL more visible suggests that it can be applied in diverse disciplinary contexts (Wiebe, 20I6).

Adaptations to the structured activity could be implemented for other class contexts though the use of the worksheet or similar reflective writing, as this was central in the current project to seeing students' skills emerge. The worksheet served as a strong foundation to beginning the conversation and having students start to explicitly engage in metacognitive work. For larger class sizes, or when class time is limited and not conducive to a jigsaw activity, instructors could assign the worksheet individually outside of class and then discuss metacognitive processes in a subsequent class.

The flexibility of this constructivist activity and its applicability for many disciplines gives instructors the freedom to find articles and readings that are relevant to their own subject area. First, identifying websites most often visited by the student population being taught can aid in their ability to connect with the style of writing. Second, choosing articles relevant to disciplinary content can support course learning goals nd help to strengthen metacognitive thinking, modeling to students the usefulness of IL skills when reading popular press. Students' reflections from this project suggest that the articles chosen may impact students' use of particular IL skills. Some variations in students' responses could be at least partially attributed to article subject matter, composition, or style. For instance, when the popular press article included more technical scientific language, students focused more on comprehension and procedural thinking in their first response. Similarly, the claims and tone of some articles were more extreme, leading students to describe more evaluation-related themes. Therefore, when adapting this activity to other content areas and selecting articles, it is important to consider instructors' pedagogical goals.

Another advantage of using this type of constructivist activity in teaching IL skills is that students' documentation of their IL thinking on the worksheet allows for instructor analysis of metacognitive growth. The worksheet makes more visible to instructors what their students are thinking and doing and how they are progressing in IL. The codes of comprehension, procedure, evaluation, and reflection emerged for students in our context; however, other codes could emerge depending upon course content and course level. Research notes the challenge for instructors in knowing if students really "get it" in terms of IL and metacognitive growth (Fulkerson et al., 2017). Using the worksheet offers instructors the opportunity to document and make visible student progress in a deliberate and systematic way.

\section{CONCLUSION}

This constructivist activity provides opportunity for facilitation of reflective writing and peer-to-peer dialogue, making metacognition visible to instructors and students and increasing IL and metacognitive skills. The comprehension, procedure, evaluation, and reflection themes that appeared in students' reflective writing on the guided worksheet demonstrate development of broader perspectives of IL skills as students practice metacognition. Thus, this article contributes to the scholarship by explaining a constructivist activity that, through guided reflection, helps to bridge the gap between IL and metacognition (Fulkerson et al., 2017). By demonstrating the ways that these two important areas of teaching and learning are interconnected, librarians and other educators can be better equipped to advocate for IL instruction 
and facilitate classroom environments that increasingly benefit students in higher education (Wiebe, 2016) and future career development (Hart Research Associates, 2015; Head, 20I2; Raish \& Rimland, 2016).

\section{REFERENCES}

Association of College \& Research Libraries. (20I5). Framework for information literacy for higher education. Retrieved from http://www.ala.org/acrl/standards/ilframework

Booth, C. (20I I). Reflective teaching, effective learning: Instructional literacy for library educators. Chicago, IL:American Library Association.

Charmaz, K., \& Belgrave, L. L. (20I5). Grounded theory. In G. Ritzer \& J. M. Ryan (Eds.), The Blackwell encyclopedia of sociology. Retrieved from https://dx.doi.org/l0.1002/978/405I655I8. wbeosg070.pub2

Cooperstein, S. E., \& Kocevar-Weidinger, E. (2004). Beyond active learning: A constructivist approach to learning. Reference Services Review, 32(2), |4|-|48. http://dx.doi. org/I0.I I08/009073204I0537658

Doctor, K. (2016,August 9).Which media companies are winning the battle for millennials? Politico. Retrieved from https:// www.politico.com/media/story/2016/08/which-media-companies-are-winning-the-battle-for-millennials-004707

Fink, L. D. (20I3). Creating significant learning experiences: An integrated approach to designing college courses. San Francisco, CA: Jossey-Bass.

Fulkerson, D. M., Ariew, S. A., \& Jacobson, T. E. (2017). Revisiting metacognition and metaliteracy in the ACRL Framework. Communications in Information Literacy, I I (I), 2I-4I. https:// doi.org/10.15760/comminfolit.2017.II.I.45

Hart Research Associates. (2015). Falling short? College learning and career success. Retrieved from Association of American Colleges \& Universities website: https://www.aacu.org/leap/ public-opinion-research/20I5-survey-falling-short

Harvey, M., Coulson, D., \& McMaugh, A. (2016). Towards a theory of the ecology of reflection: Reflective practice for experiential learning in higher education. Journal of University Teaching and Learning Practice, 13(2). Retrieved from https:// ro.uow.edu.au/jutlp/voll $3 /$ iss $2 / 2$

Head, A. J. (20I2). Learning curve: How college graduates solve information problems once they join the workplace. Retrieved from Project Information Literacy website: https://www.projectinfolit.org/uploads/2/7/5/4/2754 I 7 I//pil_fall2012_workplacestudy_fullreport_revised.pdf

Hepworth, M., \& Walton, G. (2009). Teaching information literacy for inquiry-based learning. Oxford, UK: Chandos.

Houtman, E. (20I5). “Mind-blowing”: Fostering self-regulated learning in information literacy instruction. Communications in Information Literacy, 9(I), 6-18. https://doi.org/10.15760/ comminfolit.2015.9.1.178

Kuhn, D., \& Dean, D., Jr. (2004). Metacognition: A bridge between cognitive psychology and educational practice. Theory Into Practice, 43(4), 268-273. https://doi.org//0.1207/ s I543042 I tip4304_4

Lai, E. R. (20I I). Metacognition:A literature review - Research report. Retrieved from Pearson website: https://images.pearsonassessments.com/images/tmrs/Metacognition_Literature_Review_Final.pdf

McGuire, L., Lay, K., \& Peters, J. (2009). Pedagogy of reflective writing in professional education. Journal of the Scholarship of Teaching and Learning, 9(1), 93-107. Retrieved from https:// scholarworks.iu.edu/journals/index.php/josotl/article/ view/I7/8

McKinney, P., \& Sen, B. A. (20I2). Reflection for learning: Understanding the value of reflective writing for information literacy development. Journal of Information Literacy, 6(2), I I0129. https://doi.org/ / 0.1 1645/6.2.1747

Morse, J. M. (200I). Situating grounded theory within qualitative inquiry. In R. S. Schreiber \& P. N. Stern (Eds.), Using grounded theory in nursing (pp. I-16). New York, NY: Springer.

Moseley, D., Baumfield, V., Higgins, S., Lin, M., Miller, J., Newton, D., ... Gregson, M. (2004). Thinking skill frameworks for postI6 learners: An evaluation - A research report for the Learning and Skills Research Centre. Retrieved from the ERIC website: https://eric.ed.gov/?id=ED508442

Moussa-Inaty, J. (20I5). Reflective writing through the use of guiding questions. International Journal of Teaching and Learning in Higher Education, 27(I), 104-II3. Retrieved from http:// www.isetl.org/ijtlhe/pdf/IJTLHEI 925.pdf

Pee, B., Woodman, T., Fry, H., \& Davenport, E. S. (2002).Appraising and assessing reflection in students' writing on a structured worksheet. Medical Education, 36(6), 575-585. https://doi. org/10.1046/j. I365-2923.2002.01227.x

Priceonomics Data Studio. (2017, July 19). Ranking the most popular websites by demographic. Retrieved from https://priceonomics.com/ranking-the-most-popular-websites-by-demographic/

Raish,V., \& Rimland, E. (20I6). Employer perceptions of critical information literacy skills and digital badges. College \& Research Libraries, 77(I), 87-I I 3. https://doi.org// 0.5860/crl.77.I.87

Sandars, J. (2009). The use of reflection in medical education: AMEE guide no. 44. Medical Teacher, 3 I (8), 685-695. https:// doi.org/I0.1080/0 I42 I590903050374

Schraw, G., \& Dennison, R. S. (1994). Assessing metacognitive awareness. Contemporary Educational Psychology, 19(4), 460475. https://doi.org/10.1006/ceps. 1994.1033

Sinno, S., \& Jarson, J. (20I8). Moving beyond opinion and assumption: An information literacy activity to foster students' critical thinking about popular press. Currents in Teaching and Learning, I0(I), 90-100. Retrieved from https://www. worcester.edu/Currents-Archives/

Slade, M. L., Burnham, T. J., Catalana, S. M., \& Waters, T. (2019). The impact of reflective practice on teacher candidates' learning. International Journal for the Scholarship of Teaching and Learning, /3(2). https://doi.org//0.20429/ijsotl.2019.1302I 5

Social Psychology Network. (2020). The jigsaw classroom. Retrieved from https://www.jigsaw.org/

Strauss, A., \& Corbin, J. (1994). Grounded theory methodology: An overview. In N. K. Denzin \&Y. S. Lincoln (Eds.), Handbook of qualitative research (pp. 273-285). Thousand Oaks, CA: Sage.

Tsang, A. (20I I). In-class reflective group discussion as a strategy for the development of students as evolving professionals. International Journal for the Scholarship of Teaching and Learning, 5(I). https://doi.org/ I 0.20429/ijsotl.20 I I.050I 07

Veenman, M. V. J., Van Hout-Wolters, B. H. A. M., \& Afflerbach, P. (2006). Metacognition and learning: Conceptual and methodological considerations. Metacognition and Learning, I, 3-14. https://doi.org/| 0.1007/s | |409-006-6893-0 
Vivekanandan, R. (2019, February I4). Integrating 2 Ist century skills into education systems: From rhetoric to reality. The Brookings Institution. Retrieved from https://www.brookings. edu/blog/education-plus-development/2019/02//4/integrating-2 I st-century-skills-into-education-systems-from-rhetoric-to-reality/

Wald, B. (2019, November 9). Agile teams: 5 signs of a great hire. The Enterprisers Project. Retrieved from https://enterprisersproject.com/article/2019/I I/agile-teams-5-key-skills

Wald, H. S., \& Reis, S. P. (20I0). Beyond the margins: Reflective writing and development of reflective capacity in medical education. Journal of General Internal Medicine, 25, 746-749. https://doi.org/10.1007/s | |606-010-1347-4

Weiner, S. (20II). Information literacy and the workforce: A review. Education Libraries, 34(2), 7-14. http://dx.doi. org/I0.26443/el.v34i2.306

Whitver, S. M., \& Riesen, K. K. (2019). Reiterative reflection in the library instruction classroom. Reference Services Review, 47(3), 269-279. https://doi.org/I0.I I08/RSR-04-2019-0023

Wiebe, T. J. (20I6). The information literacy imperative in higher education. Liberal Education, I01//02(4/I). Retrieved from https://www.aacu.org/liberaleducation/20 I 5-20 I 6/fall-winter/wiebe 


\section{Appendix A}

\section{Activity Worksheet}

Note:The format of this worksheet has been condensed from the original.

INDIVIDUALLY, reflect on the article you read for today's class and respond to the following questions.

\begin{tabular}{|c|c|}
\hline What was your article about? & How did you react to the article? Why? \\
\hline What are some of this article's strengths? & What are some of this article's weaknesses? \\
\hline \multicolumn{2}{|c|}{ How did you get to that conclusion? (e.g., What steps did you take? What did you think about?) } \\
\hline
\end{tabular}

\section{COMPLETE AFTER GROUP I DISCUSSION}

What advice would you give other students about how to read, analyze, and evaluate this article?

\section{COMPLETE AFTER GROUP 2 DISCUSSION}

Now that you've discussed a variety of articles, what advice would you give other students about how to read, analyze, and evaluate any article? 